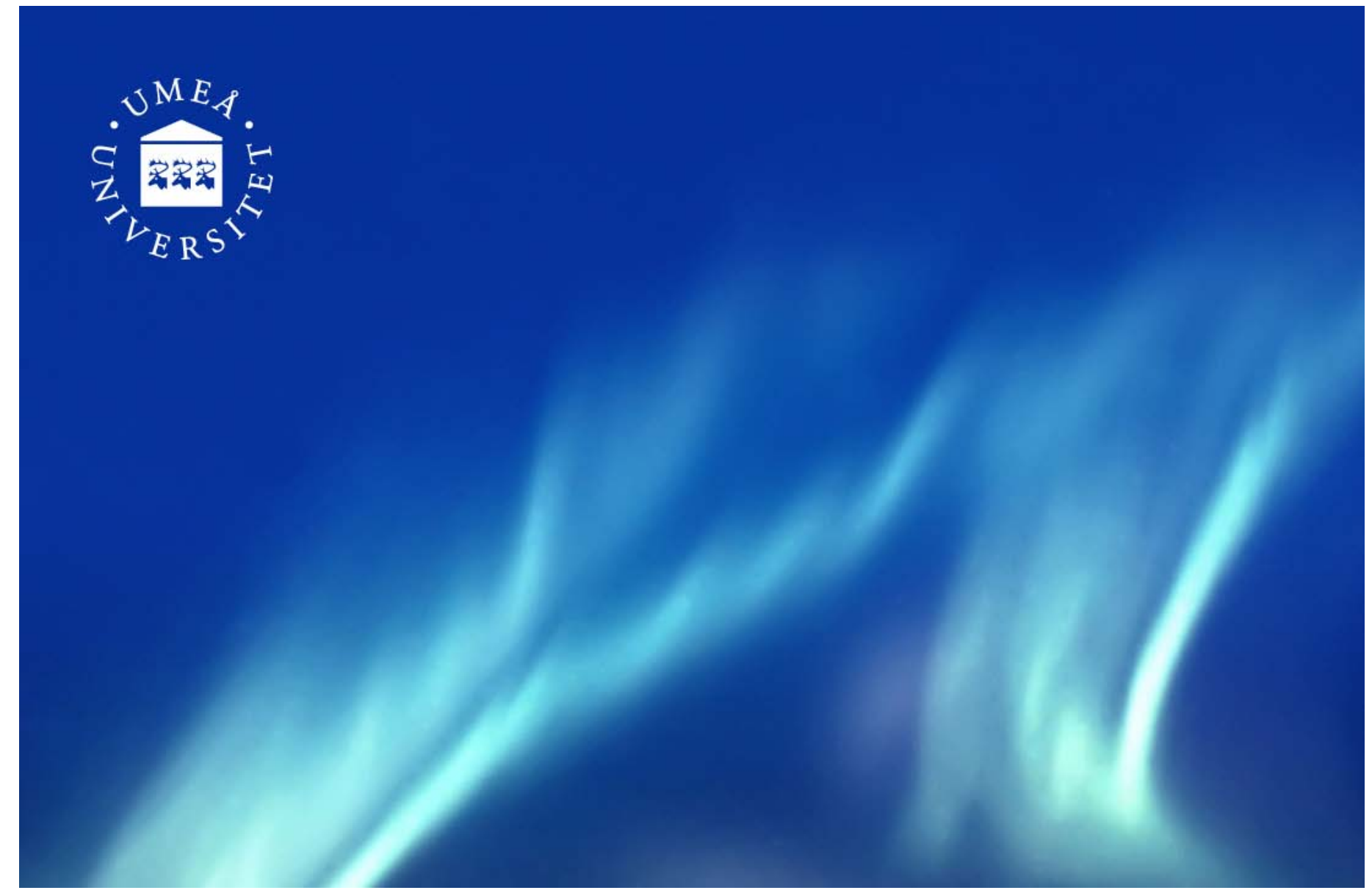

DiVA - Digitala Vetenskapliga Arkivet http://umu.diva-portal.org

This is an author produced version of a paper published in Psychopharmacology

This paper has been peer-reviewed but does not include the final publisher proof-corrections or journal pagination.

Citation for the published paper:

Helena Hedström, Marie Bixo, Sigrid Nyberg, Olav Spigset, Elisabeth Zingmark and Torbjörn Bäckstrc̈

Studies of pharmacokinetic and pharmacodynamic properties of isoallopregnanolone in healthy women

Psychopharmacology, 2009, Vol. 203, Issue: 1 pp 85-98

URL: http://dx.doi.org/10.1007/s00213-008-1372-8

Access to the published version may require subscription. Published with permission from:

Springer Verlag 


\section{STUDIES OF PHARMACOKINETIC AND \\ PHARMACODYNAMIC PROPERTIES OF \\ ISOALLOPREGNANOLONE IN HEALTHY WOMEN}

\section{Helena Hedström ${ }^{1}$, Marie Bixo ${ }^{1}$, Sigrid Nyberg ${ }^{1}$, Olav Spigset $^{2,3}$, Elisabeth Zingmark $^{1}$, Torbjörn Bäckström ${ }^{1}$}

${ }^{1}$ Umeå Neurosteroid Research Center, Department of Clinical Science, Obstetrics and Gynecology, Umeå University, Umeå, Sweden

${ }^{2}$ Department of Clinical Pharmacology, St. Olav University Hospital, Trondheim, Norway

${ }^{3}$ Department of Laboratory Medicine, Children's and Women's Health, Norwegian University of Science and Technology, Trondheim, Norway

Address correspondence to:

Torbjörn Bäckström MD, PhD, Professor

Umeå Neurosteroid Research Center

Building $5 \mathrm{~B}, 5^{\text {th }}$ Floor

Norrlands University Hospital

SE-901 85 Umeå, Sweden

E-mail: torbjorn.backstrom@obgyn.umu.se

Telephone: +46(0)90 7852144, fax: +46(0)90 776006

Keywords isoallopregnanolone, neurosteroids, pharmacokinetics, pharmacodynamics, women 


\section{Abstract}

Rationale: The pharmacokinetics and behavioral effects of isoallopregnanolone (3ß-hydoxy5 $\alpha$-pregnan-20-one) in women are not known.

Objectives: Allopregnanolone ( $3 \alpha$-hydoxy-5 $\alpha$-pregnan-20-one) is a well known neurosteriod, acting via the $\mathrm{GABA}_{\mathrm{A}}$ receptor in the human brain. The naturally occurring progesterone metabolite isoallopregnanolone is the $3 \beta$-stereoisomer of allopregnanolone. Prior studies have concluded that isoallopregnanolone has no effect on the $\mathrm{GABA}_{\mathrm{A}}$ receptor. However, an antagonistic effect of isoallopregnanolone to allopregnanolone on the $\mathrm{GABA}_{\mathrm{A}}$ receptor has been shown in animal and in vitro studies. The purpose of this study was to evaluate the pharmacokinetics and behavioral effects of isoallopregnanolone in humans.

Methods: Six healthy women were given three increasing doses of isoallopregnanolone intravenously in the follicular phase. Repeated blood samples for analyses of isoallopregnanolone and allopregnanolone concentrations were drawn. Saccadic eye movement variables, self rated sedation and mood rating scales were used during the test day. A Likert scale for prospective symptoms was used to measure daily fluctuations during the ongoing menstrual cycle.

Results: Exogenously administered isoallopregnanolone produced a dose dependent increase in the serum concentration of isoallopregnanolone. In parallel there was also a rise in the allopregnanolone concentration. There was a decrease in saccade eye movement variables, but no effect was found on self-rated sedation or mood and no changes were seen in prospective symptoms during the menstrual cycle.

Conclusions: After administration of isoallopregnanolone at a cumulative dose of $0.20 \mathrm{mg} / \mathrm{kg}$, no adverse effects were observed. There is a metabolism of isoallopregnanolone to allopregnanolone, most likely explaining the effects on the saccadic eye movements. 


\section{Introduction}

Neuroactive steroids, especially metabolites of progesterone, are potent modulators of the gamma-aminobutyric acid $\mathrm{A}\left(\mathrm{GABA}_{\mathrm{A}}\right)$ receptor and exercise rapid effects on brain function (Majewska et al. 1986; Baulieu 1991). Allopregnanolone (3 $\alpha$-hydroxy-5 $\alpha$-pregnan-20-one) is one of the most potent and well known neuroactive steroids. However, its stereoisomer, isoallopregnanolone ( $3 \beta$-hydroxy-5 $\alpha$-pregnan-20-one), does not seem to have any effect on the GABA system by itself (Lan et al. 1991; Stromberg et al. 2006).

Allopregnanolone has agonistic effects on the $\mathrm{GABA}_{\mathrm{A}}$ receptor complex in a way similar to other GABA agonists like benzodiazepines, barbiturates and alcohol. Allopregnanolone potentiates the effect of GABA on the receptor by lengthening the opening time of the chloride channel, and by increasing the frequency of channel openings, which are actions similar to both barbiturates and benzodiazepines (Belelli and Lambert 2005). Through this effect, allopregnanolone enhances inhibitory neurotransmission (Majewska et al. 1986), thus exerting sedative (Lancel et al. 1997; Timby et al. 2006) and antiepileptic effects (Landgren et al. 1998).

Isoallopregnanolone is a steroid closely related to allopregnanolone. The only structural difference from its isomer allopregnanolone is the hydroxyl group in $3 \beta$ - instead of $3 \alpha-$ position. Isoallopregnanolone by its own is, as far as we know today, without hormonal or $\mathrm{GABA}_{\mathrm{A}}$ receptor effects (Lundgren et al. 2003; Stromberg et al. 2006). Instead, isoallopregnanolone has often been used as a control when testing the specificity of allopregnanolone and its $\mathrm{GABA}_{\mathrm{A}}$ receptor enhancing effect, to show that the sterical configuration with the 3-hydroxy group is of major importance for the $\mathrm{GABA}_{\mathrm{A}}$ receptor stimulating effects of allopregnanolone (Gee et al. 1987). Furthermore, no isoallopregnanolone influence has been noted on anesthesia (Gyermek et al. 1968), anxiolysis (Bitran et al. 1991; Wieland et al. 1991; Carboni et al. 1996; Rodgers and Johnson 1998), antiepileptic effect (Kokate et al. 1994), hyperphagic effect (Chen et al. 1996) or stimulation of gastric acid secretion (Watanabe et al. 2000). Also, in in vitro experiments no effect of isoallopregnanolone of its own has been detected (Peters et al.1988; Lan et al. 1991; Lambert et al. 1995; Dayanithi and Tapia-Arancibia 1996; Le Foll et al. 1997; Calogero et al. 1998; Concas et al. 1998; Lundgren et al. 2003). 
However, it has recently been shown that isoallopregnanolone can antagonize the effect of allopregnanolone on the $\mathrm{GABA}_{\mathrm{A}}$ receptor as shown in vitro (Wang et al. 2002, Lundgren et al. 2003), on slices of brain tissue (Wang et al. 2000) and in vivo as it inhibits allopregnanolone-mediated induction of anesthesia in rats (Backstrom et al. 2005). The antagonizing effect of isoallopregnanolone on allopregnanolone seems specific as GABA, benzodiazepine or barbiturate effects are not inhibited by isoallopregnanolone (Lundgren et al. 2003; Stromberg et al. 2006).

Isoallopregnanolone is synthesized in the mammalian ovary and the serum concentration varies over the menstrual cycle and in pregnancy in parallel to progesterone and allopregnanolone (Corpechot et al. 1993; Parizek et al. 2005; Havlikova et al. 2006; Hill et al. 2007). Within the ovary, allopregnanolone originates predominantly from the corpus luteum (Ottander et al. 2005). In addition, isoallopregnanolone and allopregnanolone are synthesized from the adrenal cortex and a small amount of allopregnanolone and isoallopregnanolone can be synthesized de novo in the central nervous system (CNS) from cholesterol (Baulieu and Robel 1990; Corpechot et al.1993).

Allopregnanolone seems to be involved in several clinical conditions in both women and men. Numerous studies have reported relationships between the plasma levels of progesterone/allopregnanolone and the occurrence of epileptic seizures, mood symptoms and sedation (Backstrom 1976; Backstrom et al. 2003a; Timby et al. 2006). Allopregnanolone presence or concentrations has been studied in women in psychiatric conditions such as premenstrual dysphoric disorder (PMDD) (Rapkin et al. 1997; Bicikova et al. 1998; Monteleone et al. 2000; Girdler et al. 2001; Backstom et al. 2003b; Nyberg et al. 2007), mood symptoms during hormone therapy in the climacteric (Andreen et al. 2006) and postpartum depression (Nappi et al. 2001; Epperson et al. 2006). Altered allopregnanolone concentrations have been found in both women and in males in psychiatric conditions such as major depression and anxiety disorders (Romeo et al. 1998; Strohle et al. 2002).

In most of the menstrual cycle linked and hormone therapy studies, allopregnanolone is related to increased anxiety and thus seems to have an anxiogenic effect as there is a close relationship between increase in allopregnanolone concentrations and the development of negative mood symptoms (Backstrom et al. 2003a; Andreen et al 2006). The anxiogenic effect is surprising but this paradoxical effect of allopregnanolone is similar to what has been noted in certain sensitive individuals with any kind of $\mathrm{GABA}_{\mathrm{A}}$ receptor agonist like 
benzodiazepines (Wenzel et al. 2002), barbiturates (Masia et al. 2000) and alcohol (Miczek et al. 1997). A paradoxical effect of allopregnanolone has also been shown in animal studies (Beauchamp et al. 2000; Miczek et al. 2003) and a relation exists between allopregnanolone levels and negative mood in postmenopausal women receiving progesterone treatment (Andreen et al 2006). In the conditions where allopregnanolone has an anxiogenic effect treatment with an antagonistic substance would most likely be beneficial. Isoallopregnanolone could constitute such a therapy if it acts in a similar way in humans as it does in animals.

An objective measure of sedative effect is saccadic eye movement (SEM) measurements. A saccade is a rapid, jump-like movement of the eye from one fixation point to another, used by the eye to change the focus of the fovea. Maximal saccadic eye velocity (SEV) has a variation between subjects (Hommer et al. 1986; Sundstrom and Backstrom 1998), but is stable within subjects, both within a testing period and between testings (Gentles and Thomas 1971; Glue et al. 1991; Hommer et al. 1986; Roy-Byrne et al. 1990; Sundstrom and Backstrom 1998). Once a saccade has started, it is outside conscious control and not subjected to motivational influences (Gentles and Thomas 1971), and therefore SEV is considered to provide an objective and sensitive measure of sedation. SEV is reduced in a dose-dependent manner by benzodiazepines, pregnanolone ( $3 \alpha$-hydroxy-5 $\beta$-pregnan-20-one), alcohol and allopregnanolone (Hommer et al. 1986; Ball et al. 1991; Sundstrom et al. 1997; Sundstrom et al. 1998; Nyberg et al. 2004; Timby et al. 2006). Furthermore, benzodiazepine, pregnanolone and allopregnanolone induced increase in self-ratings of sedation, which is another pharmacological action of these compounds, is highly correlated with a reduction in SEV (Hommer et al. 1986; Ball et al. 1991; Sundstrom et al. 1998; Timby et al. 2006).

Decreased SEV and increased self-rated sedation are documented effects of allopregnanolone (Timby et al. 2006) and are suitable end point variables to study. Thus, it is reasonable to study also the effects of isoallopregnanolone on sedation and SEV. As isoallopregnanolone is given to humans for the first time and it is a metabolite of progesterone it is also of interest to investigate if any other effects appear during or after the isoallopregnanolone administration. Furthermore, the pharmacokinetic properties of isoallopregnanolone given in supraphysiological doses are not known. 
The aim of the present study was to determine the safety and pharmacokinetic properties of isoallopregnanolone and to investigate whether there is an effect on saccadic eye movement variables and self-rated sedation in healthy women.

\section{Material and methods}

\section{Subjects}

Seven healthy women aged 18 to 40 years and with regular menstrual cycles were recruited through advertisement in the local newspaper and screened for inclusion in the study. The exclusion criteria were treatment with any steroid compound (including oral contraceptives and hormonal intrauterine devices) during the last six months prior to enrollment in the study, treatment with benzodiazepines or other psychotropic drugs during the last three months preceding inclusion, and treatment with any drug (including over-the-counter drugs) during the last four weeks before inclusion. Women planning to become pregnant were excluded. Women with night work or women who had been traveling and experienced jet-lag in the week before the study day were also excluded. Further exclusion criteria were any current or previous somatic disease, any mental disorder, including PMDD, during the last six months, or a history of drug abuse or alcohol use more than six glasses of wine/beer during one day the last four weeks before the study day. The presence of psychiatric disorders was evaluated using a structured psychiatric interview, Primary Care Evaluation of Mental Disorders (PRIME-MD) (Spitzer et al. 1994), which has been validated for use in primary care settings and conforms to the criteria in Diagnostic and Statistical Manual of Mental Disorders, $4^{\text {th }}$ Edition, DSM-IV (American Psychiatric Association 1994). Prior to inclusion, physical and gynecological examinations were performed, as well as routine blood chemistry screens (Blood cell counts and plasma glucose, liver enzyme, creatinine, sodium and potassium concentrations). All subjects had negative pregnancy tests in urine and normal blood chemistry screens. They gave oral and written informed consent prior to inclusion in the study. The study procedures were in accordance with ethical standards for human experimentation, established by the Declaration of Helsinki of 1975, revised in 1983. The Regional Ethical Review Board, Umeå University and the Medical Products Agency of Sweden approved the study.

Medication 
Experimental medications were prepared by the Umeå University Hospital Pharmacy. The

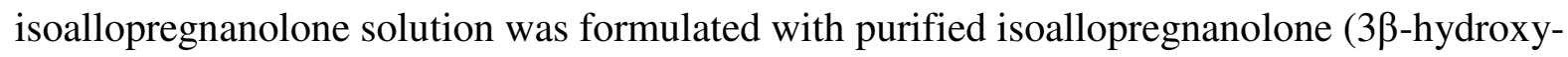
5 $\alpha$-pregnan-20-one, UC1010, Umecrine AB, Umeå, Sweden), 8 mg isoallopregnanolone dissolved in $100 \mathrm{ml}$ albumin solution (Albumin, $200 \mathrm{mg} / \mathrm{ml}$ ) using an ultrasound bath. The solution was then filtered through two sterile filters before given to the subjects. The final isoallopregnanolone concentration of each batch of solution was determined using high performance liquid chromatography (HPLC) with ultra violet (UV) absorbance (Turkmen et al. 2004). The isoallopregnanolone concentration in the final albumin solution was $0.0736 \pm 0.00807 \mathrm{mg} / \mathrm{ml}($ mean $\pm \mathrm{SD})$ isoallopregnanolone $(\mathrm{n}=6)$.

\section{Study protocol}

Isoallopregnanolone was administered in the mid/late follicular phase (day 6-13 in the menstrual cycle). To avoid interference of diurnal variations, all study patients were tested during the same time of the day. No subject was allowed to consume alcohol 24 hours prior to testing. Caffeine and tobacco use was restricted throughout the study day.

In the morning of the study day, an intravenous cannula was inserted in each forearm, one for injections of isoallopregnanolone and the other for blood sampling for the analyses of isoallopregnanolone and allopregnanolone in serum. Baseline levels of allopregnanolone and isoallopregnanolone were measured before the first injection. Three intravenous injections of isoallopregnanolone were given at 30-minute intervals, using doses of 0.04, 0.06 and 0.10 $\mathrm{mg} / \mathrm{kg}$, thus giving a cumulative dose of $0.20 \mathrm{mg} / \mathrm{kg}$. Each injection was given with an infusion rate of $2 \mathrm{mg} / \mathrm{min}$. Blood samples for measuring the serum concentrations of isoallopregnanolone and allopregnanolone were drawn at 5, 13, 18, 35, 43, 48, 65, 73, 88, 95, 105, 115, 150, 330, 600 and 780 minutes and 23 and 31 hours after the first isoallopregnanolone injection. SEV and self-rated sedation were measured 12 times during the experiment until 330 minutes after the first injection. Anxiety scale measurements were performed at baseline and continuously throughout the experiment as well as the next day. Vital functions were checked and adverse events were reported throughout the experiment until the next day.

Saccadic eye movements

Saccadic eye velocity was measured using electro-oculography (EOG) with the CSGAAS5 system, fully documented elsewhere (Marshall et al. 1985; Marshall and Richens 1989). The technique has been used in our laboratory for several years (Sundstrom et al. 1997 and 1998; 
Wihlback et al. 2001). The basic concept is to measure the difference in electric potential between the cornea and the retina. The test is performed in a quiet, semi-lit room with the patient sitting in a comfortable chair. A pillow to support the patient's head prevented head movements. EEG cup electrodes (Synetics AB, Stockholm, Sweden) with a small amount of electrode gel (Elefix, Nihon Kohden Europe, Rosbach, Germany) are used. After the skin had been exfoliated with Skinpure cream (Nihon Kohden), the electrodes are placed one $\mathrm{cm}$ lateral of the outer canthus of both eyes, with one common electrode in the center of the forehead. Electrode impedance are measured and confirmed to be less than $5 \mathrm{k} \Omega$. The subject is instructed to watch an array of light-emitting diodes (LEDs) placed at eye-level, $67 \mathrm{~cm}$ from the glabella. The target for the eye movements is an illuminated LED. The subject is asked to look at the illuminated LED and to move her eyes to the next target (the next illuminated LED) as that LED is turned off and the next one in the array is lit. Subjects are instructed not to anticipate targets.

The target movements take place at 1.5-second intervals. A fixed, sequence of 4 x 24 targets producing target steps of 10,20,30, and 40 degrees, is displayed with a brief rest in between. The first four of these 24 target steps of each session are not included in the subsequent analyses, in order to allow the subject to adjust to the procedure. The EOG is DC amplified and low-pass filtered $(-3 \mathrm{~dB}$ at $50 \mathrm{~Hz})$ before being digitized to 12-bit resolution at a sampling frequency of $250 \mathrm{~Hz}$. A personal computer controls the target movements and digitalizes the waveform using an analogue-digital converter. The 80 individual EOGs, resulting from the 4 x 20 target steps, are stored and analyzed off-line according to the method of Marshall and Richens (Marshall and Richens 1989). First, the digitalized data from each target displacement are processed to locate saccades. To avoid preemptive saccades and blinking artifacts, only saccades initiated 50 to 400 milliseconds after target movements are included. Also, to be considered a saccade, the recorded eye movement has to display a velocity of more than 100 degrees/second. In addition, each saccade is analyzed to determine the size of the saccade in degrees, the peak saccadic velocity, and latency from target movement to onset of saccade. Saccade accuracy is determined by comparing the actual eye position at the end of the saccade with the attempted target. SEV is further processed by plotting a velocity-saccade size curve, known as the main sequence (Baloh et al. 1975). The relationship between saccade size and peak velocity is important since it remains constant even when voluntary control of saccades is attempted. The main sequence is fitted by a quadratic equation to the peak velocity data using the calculated saccade angle as the independent variable. Carrying out the fitting procedure twice and weighing the second fit with the inverse of the square of the 
residuals from the first fit minimized the influence of outliers in the data. The values of peak velocity for 10-, 20-, 30- and 40-degree saccades are calculated by interpolation. Saccades with amplitudes of 30 degrees are chosen for further analyses as SEV reaches a maximum at approximately 30-35 degrees of angular movement (Baloh et al. 1975). SEV is evaluated as an objective way to estimate sedation with a small intra individual variation (Hommer et al.1986). The computer program that is generating and calculating the saccades is developed by Cardiff Clinical Trials Ltd and is well documented (Richens et al. 1993).

\section{Visual analogue ratings}

A visual analogue scale (VAS) was used for the test person to rate sedation and subjective feelings of alcohol-like intoxication (McCormack et al. 1988). The scale measured from 0 to a $10 \mathrm{~cm}$ where 0 equaled complete absence of sleepiness/feelings of intoxication and 10 represented falling asleep/feelings of heavy intoxication. Subjective ratings of sedation and intoxication were made at baseline, after each of the saccadic eye measurements, and at 600 and 780 minutes.

\section{Mood rating scales}

At baseline, three scales were used to measure the subject's tendency to develop anxiety and the actual anxiety level from different aspects. The Swedish version of Spielberger's State Trait Anxiety Inventory (STAI, state subscale), Anxiety Sensitivity Inventory (ASI) and Panic Symptom Scale (PSS) were used. The difference in anxiety level during the test was measured continuously with the State Anxiety and Discomfort Scale (SADS). STAI and PSS were also used after the trail to register anxiety symptoms or relief of anxiety during the first 24 hours after the test.

STAI, State-Trait Anxiety Inventory comprises 20 items tapping anxiety proneness and anxiety in relation to the experimental situation with a total range of scores from 20 to 80 (Spielberger et al. 1983).

ASI, Anxiety Sensitivity Index. The ASI is a questionnaire comprising 16 items that express concerns about the possible aversive consequences of anxiety symptoms (Reiss et al. 1986). The Swedish version of ASI has satisfactory psychometric properties (Hellstadius 2000). Respondents indicate their degree of endorsement on 5-point scales that range from 0 (very little) to 4 (very much), and total scores range from 0-64. The ASI manual reports a mean of 19.01 ( $\mathrm{SD}=9.11$ ) for non patients (Peterson and Reiss 1992). Mean score for panic disorder patients was reported to be 36.2 (Taylor et al. 1992). 
PSS, Panic Symptom Scale is a DSM-IV-derived panic symptom scale (Bradwejn et al. 1991), where subjects retrospectively rate the maximum intensity of panic symptoms on 18 items ( $0=$ not present, $1=$ mild, $2=$ moderate, $3=$ severe, $4=$ extremely severe $)$. The sum of intensity ratings was measured by summarizing each item score on the PSS (range 0-72).

SADS, State Anxiety and Discomfort Scale is a global measure of subjective discomfort. This scale was earlier evaluated in pharmacological tests on humans, where quick changes in anxiety levels could be detected (Radu et al. 2002). The SADS is a simple Likert self-rating scale, ranging from 0 (no discomfort) to 5 (worst imaginable discomfort). Intermediate levels were 1 (slight discomfort), 2 (moderate discomfort), 3 (severe discomfort) and 4 (very severe discomfort). The SADS is a global measure of the three aspects of anxiety, namely effect, somatic symptoms and cognitions (Aluoja et al. 1997). SADS was measured bedside repeatedly during the test day at 19 times.

\section{Likert scale for prospective symptom ratings}

The subjects performed daily mood ratings each evening from the first day of menstruation in the actual menstrual cycle until the next menstruation started. This scale was used to measure day-to-day fluctuations in mood and has been used in our laboratory in several prior studies. The scale comprises menstrual bleeding and 15 physical and mood symptoms relevant for the diagnosis Premenstrual Dysphoric Disorder (PMDD) according to DSM-IV (American Psychiatric Association 1994; Sundstrom et al. 1999a).

Assays of isoallopregnanolone and allopregnanolone

Serum concentrations of isoallopregnanolone and allopregnanolone were measured in duplicates by radio-immunoassay (RIA) after pre-assay diethylether extraction and separation with high performance liquid chromatography (HPLC). Plasma $(0.4 \mathrm{ml})$ was pipetted into a cylindrical flat bottom glass vial of $20 \mathrm{ml}$ volume, and water $(0.5 \mathrm{ml})$ and diethylether $(3.0$ ml) were added. The samples were then allowed to stand on an orbital shaker for ten minutes. Following the liquid-liquid extraction, the vials were transferred into an ethanol/dry ice bath. The water phase became frozen, and the ether phase was decanted and evaporated under a stream of nitrogen gas. To determine the analytical recovery of the technique, known amounts of isoallopregnanolone $(750 \mathrm{pg} / \mathrm{ml})$ were added to two extraction vials and the solvent was evaporated to dryness under a stream of nitrogen before addition of plasma. Prior to the HPLC analysis, the samples were resolved in $1000 \mu \mathrm{l}$ of a 50:50 ethanol and water mixture $(\mathrm{V} / \mathrm{V})$. Recovery in the allopregnanolone assay was made by adding a known amount of 
radioactive allopregnanolone before the assay and the recovered amount was measured after the work up procedure.

\section{High Performance Liquid Chromatography (HPLC)}

The chromatographic system consisted of a Waters 1515 Isocratic HPLC-Pump (Waters AB, Sweden), which delivered a mobile phase containing methanol and water, 60:40, V/V) at a flow rate of 1.0ml/min. A Waters 717 plus Autosampler (Waters AB, Sollentuna, Sweden) was used for injection of standard solution and plasma samples (200 $\mu \mathrm{l})$ into a Symmetry C18 $3.5 \mu \mathrm{m} 75 \mathrm{~mm}$ x $4.6 \mathrm{~mm}$ i.d. separation column (Waters AB). Detection of retention times of standards and cross-reacting steroids was at $206 \mathrm{~nm}$ using a Waters 2487 Dual $\lambda$ Absorbance Detector (Waters AB). The detector output was recorded on a PC-based Waters Breeze Chromatography Software (version 3.20). In the preparative HPLC $1.5 \mathrm{ml}$ fractions were symmetrically collected around the peak retention time for isoallopregnanolone or allopregnanolone, retention was found from injection of a standard sample. A Waters Fraction Collector II was used for collection of samples, for further analysis with radioimmunoassay. No cross-reacting steroids had retention times close to the collected fractions. Retention time for isoallopregnanolone ( $5 \alpha$-pregnan-3 $\beta$-ol-20-one) is 18.9 minutes and for allopregnanolone

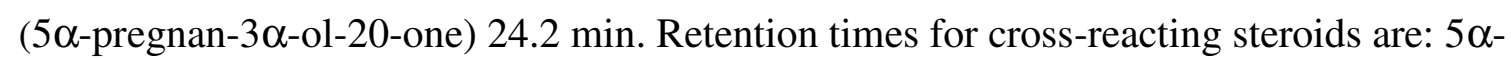
pregnan-20 $\beta$-ol-3-one $26.7 \mathrm{~min}, 5 \beta$-pregnan-3 $\alpha$-ol-20-one $22.5 \mathrm{~min}, 5 \beta$-pregnan-3,20-dione $19.4 \mathrm{~min}, 4$-pregnen-3 $\alpha$-ol-20-one $18.5 \mathrm{~min}, 5 \beta$-pregnan-3 $\beta$-ol-20-one $17.9 \mathrm{~min}, 5 \alpha$-pregnan3,20-dione $17.0 \mathrm{~min}, 5$-pregnen-3 $\beta$-ol-20-one (pregnenolone) $14.7 \mathrm{~min}, 5 \alpha$-pregnan-3 $\alpha, 21$ diol-20-one $10.1 \mathrm{~min}$, preg-4-ene-3,20-dione (progesterone) $9.4 \mathrm{~min}$ and 4-pregnen-20 $\alpha$-ol-3one $9.2 \mathrm{~min}$. The eluted fraction for isoallopregnanolone and allopregnanolone was dried down in a Speed Vac spd 2010 system (Thermo Savant, Holbrook, USA).

\section{Radioimmunoassay (RIA) of isoallopregnanolone}

For the isoallopregnanolone (3beta-hydroxy-5alpha-pregnan-20-one) analysis, an antibody for pregnenolone (Pregnenolone-3-monohemisuccinate-HSA) (ICN Pharmaceuticals, Inc Orangeburg, NY, USA) was used as it also binds isoallopregnanolone. Cross-reactivity with isoallopregnanolone was $26.6 \%$, allopregnanolone $13 \%, 5 \alpha$-pregnan-3,20-dione 7\%, $5 \beta$ pregnane-3 $\beta$-ol-20-one $<1 \%, 5 \beta$-pregnan-3 $\alpha$-ol-20-one $<1 \%, 5 \alpha$-pregnan- $3 \alpha, 20 \alpha$-diol $<1 \%$. Radioactive steroid tracer used was $\left[7-{ }^{3} \mathrm{H}(\mathrm{N})\right]$-pregnenolone purchased from NEN Life Science Products, Boston, MA, USA. The lowest detectable amount of isoallopregnanolone 
(two standard deviations above the blank mean) was 0.11 pmol or $35.8 \mathrm{pg}$. The recovery of the extraction and including the HPLC procedure was for isoallopregnanolone 95\%. Each isoallopregnanolone sample was measured in quadruples and all samples from each subject were run in the same assay. The standard curve was established by preparing duplicate tubes containing seven concentrations of unlabeled isoallopregnanolone to give a range from 0 to $2.5 \mathrm{pmol}(0-800 \mathrm{pg})$ isoallopregnanolone (data not shown). The antiserum was used in a dilution of 1/320; The antibody solutions was prepared with $\left[7-{ }^{3} \mathrm{H}(\mathrm{N})\right]$-pregnenolone $3 \times 106$ cpm/32 ml solution containing $65 \mathrm{mM}$ boric acid (Merck, Darmstadt, Germany) buffer, $\mathrm{pH}=8.0$, bovine serum albumin $100 \mathrm{mg} / \mathrm{ml}$ (Sigma, St Louis, MO, USA), human gamma globulin solution $20 \mathrm{mg} / \mathrm{ml}$ (Octapharma, Stockholm, Sweden) and antibody in milliliter ratio of the different solutions: 30:1:1:0.010. The solution was allowed to equilibrate overnight at $8^{\circ} \mathrm{C}$. Antibody solution $(200 \mu \mathrm{l})$ was added to all standard and sample tubes, and the mixture allowed to stand overnight at $8^{\circ} \mathrm{C}$. After the addition of $200 \mu$ saturated ammonium sulfate, each tube was again mixed and centrifuged at 20,000 RPM for $20 \mathrm{~min}$. Thereafter, the supernatant was aliquoted into a counting vial and diluted with $3.0 \mathrm{ml}$ Optiphase scintillation medium (Perkin Elmer, Shelton, USA). The samples were counted in a RackBeta (Wallac, Turku, Finland) scintillation counter. The sensitivity of the assays was $0.08 \mathrm{pmol}$ (25 pg), with an intraassay coefficient of variation of $8.5 \%$ and an interassay coefficient of variation of $10.7 \%$.

\section{Radioimmunoassay (RIA) of allopregnanolone}

The samples were analyzed using a polyclonal rabbit antiserum (a kind gift from RH Purdy, The Scripps Research Institute La Jolla, CA, USA, Purdy et al. 1990). The method has been described in details earlier (Timby et al. 2006) and here only briefly described. The antiserum is raised in rabbits against $3 \alpha$-hydroxy-20-oxo-5 $\alpha$-pregnan-11-yl carboxymethyl ether coupled to bovine serum albumin (Purdy et al. 1990). The cross-reactivity of the antibody is shown in earlier publications (Purdy et al. 1990, Timby et al. 2006). The standard curve was established by preparing duplicate tubes containing eight concentrations of unlabeled allopregnanolone to give a range from 0 to $400 \mathrm{pg}$. Rabbit antiserum was used in a dilution of $1 / 5000$ and the antibody solutions were prepared with $[11,12]^{3} \mathrm{H}$-allopregnanolone (NEN), $3 \mathrm{x}$ $10^{6} \mathrm{cpm} / 32 \mathrm{ml}$ solution containing $65 \mathrm{mM}$ boric acid (Merck) buffer, $\mathrm{pH}=8.0$, bovine serum albumin $100 \mathrm{mg} / \mathrm{ml}$ (Sigma), human gamma globulin solution $20 \mathrm{mg} / \mathrm{ml}$ (Octapharma) and antibody in ml ratio solution of: 30:1:1:0.006 making a total solution of $32.006 \mathrm{ml}$. The rest of the assay was made as described above for isoallopregnanolone. The sensitivity of the assays 
were $25 \mathrm{pg}$, with an intra-assay coefficient of variation for allopregnanolone of $6.5 \%$ and an inter-assay coefficient of variation of $8.5 \%$. The recovery of allopregnanolone was $98 \%$ and the results are compensated for recovery.

Pharmacokinetic analysis

Baseline serum concentrations $\left(\mathrm{C}_{0}\right)$, concentrations 5 minutes after each intravenous injection $\left(\mathrm{C}_{5}, \mathrm{C}_{35}\right.$ and $\left.\mathrm{C}_{65}\right)$, maximum serum concentrations $\left(\mathrm{C}_{\max }\right)$, and the time to achieve maximum serum concentrations $\left(t_{\max }\right)$, were obtained directly from the measured values. Before the pharmacokinetic calculations were carried out, the baseline isoallopregnanolone and allopregnanolone concentrations were subtracted from the measured values obtained 5-1860 minutes later, and only the net concentrations were used for further pharmacokinetic analyses. In all subjects, the baseline isoallopregnanolone concentrations were below $1.9 \%$ of the maximum concentrations and the baseline allopregnanolone concentrations were below $1.3 \%$ of the maximum concentrations. Pharmacokinetic parameters were calculated by means of the Kinetica program package, version 4.3 (InnaPhase Corporation, Philadelphia, PA, USA), using a non-compartment model. The parameter estimates describing the elimination phase of the log-concentrations of isoallopregnanolone and allopregnanolone $\left(\lambda_{z}\right)$ were calculated using the concentrations from 330 to 1860 minutes after the first dosage, as this gave the bestfit regression lines. The elimination half-lives $\left(t_{1 / 2}\right)$ were calculated as $\ln 2 / \lambda_{z}$. Areas under the curve (AUC) were calculated using a mixed log-linear method with extrapolation to infinity. The mean extrapolated AUC was $11.2 \%$ of the total AUC for isoallopregnanolone and 22.7 $\%$ of the total AUC for allopregnanolone. Clearances (CL) were calculated as dose/AUC and the volumes of distribution $\left(\mathrm{V}_{\mathrm{d}}\right)$ were calculated as CL/ $\lambda_{\mathrm{z}}$.

\section{Statistics}

Saccadic eye velocity parameters and self-rating scores were calculated as difference from baseline at each time-point, e.g. delta degrees /second and delta sedation scores. The daily symptom rating score data were centered on the onset of menstrual bleeding and the test day. The saccadic eye velocity parameters were analyzed by one-way ANOVA (analysis of variance) with repeated measures, least significant difference test were used as post hoc test. The SPSS version 11 statistical package was used for analyses. $P$ values of less than 0.05 were considered to be statistically significant. 


\section{Results}

Seven women were included but only six completed the study. The seventh subject was excluded on the test day because she developed a vasovagal reaction when the intravenous cannula was inserted; she was never given any test injection. Demographic data of the study group is presented in Table 1.

The concentrations of isoallopregnanolone at baseline and after each injection are shown in Table 2, Figure 1 and Figure2, bottom panel. In parallel to increasing concentrations of isoallopregnanolone there was also a rise in allopregnanolone concentrations with a significant correlation between the isoallopregnanolone and allopregnanolone concentrations $(\mathrm{r}=0.484 ; \mathrm{p}<0.001)$.

The pharmacokinetic parameters of isoallopregnanolone and allopregnanolone are described in Table 2. The first dose of isoallopregnanolone was $0.04 \mathrm{mg} / \mathrm{kg}$, the second dose $0.06 \mathrm{mg} / \mathrm{kg}$ and the third dose $0.10 \mathrm{mg} / \mathrm{kg}$. Five minutes after the first dose the concentration of isoallopregnanolone was $27.5 \mathrm{nmol} / \mathrm{l}$, after the second injection the concentration rose by 33.3 $\mathrm{nmol} / \mathrm{l}$, and after the third by another $77.2 \mathrm{nmol} / \mathrm{l}$. The theoretic cumulative concentration after the second injection is $68.75 \mathrm{nmol} / \mathrm{l}$ (1.5 times the value after the first injection of isoallopregnanolone), and $137.5 \mathrm{nmol} / \mathrm{l}$ (2.5 times) at the third injection. These values are very close to the values measured at 5 minutes after these injections (Table 2), indicating a dose-related increase in the serum concentration of isoallopregnanolone. The maximum serum concentration of isoallopregnanolone was $143 \mathrm{nmol} / 1$, achieved at 67.7 minutes. The maximum serum concentration of allopregnanolone was $22.8 \mathrm{nmol} / 1$, which is $16 \%$ of the maximum concentration of isoallopregnanolone, and occurred 6 minutes later, at 74.0 minutes.

In Figure 2, top panel, the effects on sedation are shown. No significant changes occurred in sedation following the three injections of isoallopregnanolone.

Figure 2, middle panel, shows the changes in saccadic eye velocity during the test. There was an overall significant decrease in $\operatorname{SEV}(\mathrm{F}(14,70)=3.27 ; \mathrm{p}<0.001)$. The post hoc test showed significant decreases in SEV 5 and 13 minutes after the first injection $(\mathrm{p}=0.014-0.027)$ and 5 and 18 minutes after the second injection $(\mathrm{p}=0.007-0.024)$. After the third injection there were significant decreases during the first 35 minutes ( $\mathrm{p}=0.019-0.049)$, not at 45 minutes, but then 
again at 55 minutes ( $\mathrm{p}=0.008$ ). From 150 minutes after the first injection SEV had returned to baseline again.

The effect on vital functions is shown in Table 3. There were no significant changes in the systolic and diastolic blood pressure after the injections, although there was a significant decrease in heart rate during the course of the study day (Table $3, F(5,25)=6.12 ; \mathrm{p}<0.001$ ). The respiration frequency showed no significant change. The menstrual cycle length of the test cycle was $27.7 \pm 1.1$ days, which was not significantly different from the reported cycle length of $28.8 \pm 0.6$ days prior to the test, (Table 1 , mean \pm SEM).

During the test the six women performed four different psychological tests. With the ASI test at baseline, all women were within a low anxiety range (score 0-10), except one subject with a score of 12. The ASI test has a total range from 0 to 64 (Grant et al 2007). PSS and STAI revealed no significant changes from baseline until the day after the test (PSS: $0.33 \pm 0.33$ versus $0.33 \pm 0.21$; STAI: $41.8 \pm 2.1$ versus $42.8 \pm 2.6$ ). No fluctuations in anxiety level were revealed by SADS when used repeatedly from baseline through the test day and until 31 hours after the first injection.

To investigate whether isoallopregnanolone had any effect on mood symptoms the data were centered around the day of the test injection. Summarized positive, negative and physical symptoms as well as the individual symptoms were investigated from five days prior to the test until ten days after the test are shown in Figure 3. There were no significant changes in any symptoms after the injections.

Summarized positive, negative and physical symptoms were plotted in an ideal menstrual cycle of 28 days by centering the score data around the onset of menstruation (data not shown). Summarized positive symptoms showed no significant variation during the cycle. Summarized negative mood and physical symptoms showed a slight but significant overall variation within the cycle $(\mathrm{F}(27,135)=1.62 ; \mathrm{p}=0.039$ and $\mathrm{F}(27,135)=2.34 ; \mathrm{p}<0.001$, respectively). For summarized negative mood symptoms there was a significant overall variation but no single day showed significant symptom severity over the other days. For summarized physical symptoms the first and the last day of the cycle showed a significant symptom increase compared to the follicular phase $(\mathrm{p}<0.05, \mathrm{p}=0.01)$. 
When statistics were calculated for each of the 16 symptoms except menstrual bleeding, in the ideal menstrual cycle, some of the symptoms showed significant variation. These were breast tenderness $(\mathrm{F}(27,135)=0.300 ; \mathrm{p}<0.001)$, swelling $(\mathrm{F}(27,135)=2.63 ; \mathrm{p}<0.001)$ and sleeping problems $(\mathrm{F}(27,135)=1.66 ; \mathrm{p}=0.032)$. Decreased interest for daily activities $(\mathrm{F}(27,135)=2.32$; $\mathrm{p}=0.001$ ) was only significant at onset of the menstrual bleeding. Daily life impairment showed significant variation $(\mathrm{F}(27,135)=2.46 ; \mathrm{p}<0.001)$ being higher in cycle day 1 and $3(\mathrm{p}=$ 0.046-0.022 and $\mathrm{p}=0.042-0.041$ ) compared with the last two days of the cycle. Cycle day 27 and 28 had significant less impairment then cycle day 1-3.

\section{Discussion}

The pharmacokinetics of isoallopregnanolone, given as an intravenous injection to humans, has not been studied before. One of the main findings of the present study was a dose proportional increase in the serum concentration of isoallopregnanolone after intravenous administration of a cumulative dose of $0.20 \mathrm{mg} / \mathrm{kg}$. A second finding was a rather slow elimination of isoallopregnanolone, with a half-life of about 850 minutes. There was a difference in response to isoallopregnanolone on saccadic eye velocity compared to self-rated sedation. No changes related to isoallopregnanolone injection were noted in the mood symptom ratings.

In parallel to the rise in concentration of isoallopregnanolone, but with a slight delay, there was also a rise in serum concentration of allopregnanolone. The obvious explanation is that some isoallopregnanolone has been metabolized to allopregnanolone. This theory is supported by earlier findings showing that allopregnanolone and isoallopregnanolone serum concentrations are highly correlated both during the follicular and the luteal phase of the menstrual cycle (Havlikova et al. 2006). Furthermore, the 3alpha hydroxylase is effective in both direction and when allopregnanolone is given to animals there is an increase in isoallopregnanolone concentration so one can expect that when isoallopregnanolone is given allopregnanolone should increase (Vallee et al. 2000).

In the present study, clearance of isoallopregnanolone was $32.1 \mathrm{ml} / \mathrm{min} / \mathrm{kg}$. This result should be compared with previously reported values of $32.6 \mathrm{ml} / \mathrm{min} / \mathrm{kg}$ for allopregnanolone (Timby 
et al. 2006) and $61.0 \mathrm{ml} / \mathrm{min} / \mathrm{kg}$ for pregnanolone (Sundstrom et al. 1999b). Thus, the clearance of allopregnanolone and isoallopregnanolone appears to be about the same, indicating a similar elimination rate of the two substances.

Allopregnanolone has a hydroxyl group in a planar $3 \alpha$ position compared to the angel position (the $3 \beta$ position) in relation to the steroid skeleton for isoallopregnanolone. Steroids with a hydroxy group in the $3 \alpha$ position have been reported to be glucuronized at a higher degree than steroids with a hydroxy group in the $3 \beta$ position (Jin et al. 1997), most likely because the $3 \alpha$ position better fits the active site on the conjugation enzyme. The amount of allopregnanolone glucuronized might therefore be higher than the corresponding amount of isoallopregnanolone. As the clearance values for these two substances nevertheless are about the same, other metabolic pathways (or active renal excretion pathways) would be expected to contribute to the elimination of isoallopregnanolone to a higher degree than for allopregnanolone. Such a metabolic pathway might be degradation via cytochrome P-450 3A4 (CYP3A4), which is known to be involved in the metabolism of many sex hormones (Yamazaki and Shimada 1997; Niwa et al. 1998; Tsuchiya et al. 2005).

The elimination half-life of allopregnanolone in the present study was about 1100 minutes, which is more than four times the elimination half-life of allopregnanolone of 260 minutes reported previously (Timby et al. 2006). This most obvious reason is a continuous production of allopregnanolone from isoallopregnanolone in the present study, implying that the half-life calculated for allopregnanolone is not based upon data from a true elimination phase. Compared to the previously reported elimination half-life of allopregnanolone (Timby et al. 2006), the elimination half-life of isoallopregnanolone of about 850 minutes in the present study is also rather long. The solvent might be of importance for the half-life by creating a possible depot from which the substance is slowly released, as shown for pregnanolone (Carl et al. 1994; Sundstrom et al. 1999b). However, both allopregnanolone and isoallopregnanolone were administrated in a similar albumin solution. Thus, the most likely explanation for the differences in elimination half-lives, despite the same clearance values, is a higher volume of distribution for isoallopregnanolone. In fact, the volume of distribution for isoallopregnanolone in the present study was $361 / \mathrm{kg}$, whereas it was $12.51 / \mathrm{kg}$ for allopregnanolone in the study by Timby et al (2006). We have not investigated the tissue 
distribution in more detail in the present study, but the differences in retention times in the HPLC suggest somewhat higher lipid solubility for isoallopregnanolone.

The method used for the isoallopregnanolone assay is RIA after HPLC separation of crossreacting steroids. The antiserum used is made against pregnenolone and therefore not specific against isoallopregnanolone but bounds isoallopregnanolone sufficiently for a standard curve to be obtained. To avoid overestimation of isoallopregnanolone by pregnenolone and crossreacting steroids a HPLC separation was used in advance. A number of cross-reacting steroids were separated from isoallopregnanolone with this procedure (see method). The study was carried out in the follicular phase of the menstrual cycle when the endogenous concentrations of isoallopregnanolone and allopregnanolone are low. The baseline endogenous concentration obtained in the present study is in the upper range of concentrations reported in the literature when using HPLC/RIA and gas chromatography-mass spectrometry as analytical techniques (Romeo et al. 1998; di Michele et al. 2003; Schule et al. 2003; Murphy et al. 2004; Havlikova et al. 2006). The concentrations measured in the present study are also higher than those obtained during the mid follicular phase in women at noon using the same assay method as in the present study $(0.22 \pm 0.77 \mathrm{nmol} / \mathrm{l}($ mean $\pm \mathrm{SD})$, range 0.1 to $1.1 \mathrm{nmol} / \mathrm{l}, \mathrm{n}=77$, unpublished results). In addition, the allopregnanolone concentrations (Table 2) are in the upper normal range at baseline and higher than levels during mid follicular phase in women but in the same range as samples taken in early follicular phase (Nyberg et al. 2007).

There are two factors that may explain the baseline levels. The first factor is that the baseline samples are all taken early in the morning, that is at a time when ACTH-stimulated steroid production from the adrenals are high. During the follicular phase the ACTH-stimulated adrenals is the major source of serum allopregnanolone and most likely also of isoallopregnanolone (Torres et al. 2001, Genazzani et al 2002). The second factor is that the situation was somewhat stressful. The subjects knew that they were about to receive a compound never given to humans before, and electrodes for oculography had been mounted and intravenous cannulas inserted prior to testing. It is known that allopregnanolone and most likely also isoallopregnanolone increase after stress both in humans and animals (Droogleever et al. 2004; Purdy et al. 1991). The allopregnanolone concentrations at baseline in our subjetcs are slightly lower than in amenorrheic patients known to have a high adrenal stimulation (Genazzani et al 2002). These factors may explain the somewhat higher baseline 
concentrations of isoallopregnanolone and allopregnanolone in the follicular phase in the present study.

However, after the injections exogenously administered isoallopregnanolone will dominate in the sample and the most likely metabolites and cross-reacting steroids like pregnenolone and allopregnanolone were separated with the preceding HPLC.

The current study shows no significant influence on self rated sedation after injections of isoallopregnanolone, but there is a significant decrease in saccade velocity during the test. The effect on SEV was not anticipated, as earlier in vitro studies by our group have not shown any effect, whatsoever, directly on the $\mathrm{GABA}_{\mathrm{A}}$ receptor (Lundgren et al. 2003). A possible explanation to this finding is that metabolism of isoallopregnanolone to allopregnanolone occurs and that the effect on the saccade velocity actually is an effect of allopregnanolone. This theory is supported by the course of events during the study. The effect on SEV lasted from the first injection of isoallopregnanolone until 150 minutes after the last injection, which is longer than the effect produced by allopregnanolone directly where the effect declined already after 45 minutes (Timby et al. 2006). In the present study, as well as in the Timby study, the maximum concentrations of the steroid injected were reached 5 minutes after the last injection. In the Timby study the maximum concentration of allopregnanolone was about $70 \mathrm{nmol} / \mathrm{l}$ after a cumulative dose of $0.09 \mathrm{mg} / \mathrm{kg}$ and the maximum concentration of isoallopregnanolone in our study was almost $140 \mathrm{nmol} / 1$ after a cumulative dose of 0.20 $\mathrm{mg} / \mathrm{kg}$. However, in the present study, there was a delay of 6 minutes for the concentration peak of allopregnanolone $(20 \mathrm{nmol} / \mathrm{l})$ to occur compared to the isoallopregnanolone peak. The concentration of isoallopregnanolone decreased quite fast, but for allopregnanolone the concentration made a plateau and was almost constant until 35 minutes after the last isoallopregnanolone injection (Figure 2 bottom panel). In addition, the cumulative dose of isoallopregnanolone was quite high, which might facilitate a substantial metabolism to allopregnanolone. Finally, an additional metabolism of isoallopregnanolone to allopregnanolone might also take place within the central nervous system without being detected in the periphery. The 3- $\alpha$-hydroxylase is effective in both directions, and the conversion of isoallopregnanolone to allopregnanolone is probably higher in the brain than in plasma. A higher conversion of allopregnanolone to isoallopregnanolone in the brain compared to plasma has been shown in rodents and it is likely that similar conversion exists in humans (Vallee et al 2000). Due to high concentration of isoallopregnanolone the metabolism is most probably in the direction from isoallopregnanolone to allopregnanolone and a higher 
allopregnanolone concentration can be assumed in the brain than in plasma. However, we can not exclude the possibility that isoallopregnanolone has an effect of its own, even though earlier in vivo and in vitro studies have not been able to show it (Gyermek 1968; Lundgren et al. 2003; Stromberg et al 2006).

Interestingly, no effect on sedation was noted in the present study, although a significant decrease in SEV was observed. Several explanations to this finding are possible. The lack of effect on sedation might be due to an antagonistic effect of isoallopregnanolone on allopregnanolone. In vivo studies in rats show an antagonistic effect of isoallopregnanolone on allopregnanolone-induced anesthesia (Backstrom et al. 2005). Another explanation to the lack of effect on sedation is that the concentration of allopregnanolone was less than one third of the concentrations produced in earlier studies were a distinct effect on sedation was found (Timby et al. 2006). Thus, higher concentrations than in the present study might be necessary for such an effect. SEV might also be a more sensitive measurement of sedation than subjective VAS scores

It has previously been shown that sedation and saccadic eye velocity can show different responses to $\mathrm{GABA}_{\mathrm{A}}$ stimulation. For instance, thyrotropin-releasing hormone reverses benzodiazepine-induced sedation but not the slowing of saccadic eye velocity (Glue et al. 1992) An explanation to the differential effects on sedation and SEV might be differences in metabolism and/or receptor interaction in different areas of the brain so that the antagonistic effect is more pronounced in areas involved in sedation compared to areas controlling the saccadic eye velocity.

Since one of our hypotheses is that allopregnanolone, isoallopregnanolone and other neurosteroids are involved in the etiology of PMDD it was important to detect any effect on mood and anxiety during the experiment. However, no acute effects were noted and no delayed effects were seen during a period of ten days after the experiment. It is also interesting to notice that there was no significant change in the length of the menstrual cycle or in mood and physical symptoms during the menstrual cycle in which the test was performed. Even though some cyclic symptom changes were observed at the end of the menstrual cycle these were considered to be the normal cyclic symptom variations seen in most women premenstrually. No significant changes occurred on the test day or during the days following the test. 
Isoallopregnanolone seems to be safe when given intravenously at a cumulative dose of 0.20 $\mathrm{mg} / \mathrm{kg}$, as no significant adverse events were reported and no significant effects on vital functions were noted. A slight decrease in heart rate was detected after each injection but that was probably an effect of decreased stress and rest during the test day. However, it should be emphasized that the number of subjects included is far too low to detect infrequent adverse reactions. Moreover, if given in higher doses, the frequency of adverse reactions might increase.

In conclusion, isoallopregnanolone seems to be safe to give intravenously to healthy women at the present doses and does not interfere with the menstrual cycle. For the first time, pharmacokinetic properties of isoallopregnanolone have been investigated in humans. Finally, isoallopregnanolone has an effect on saccadic eye movement, although not on self-rated sedation, most probably due to the metabolism to allopregnanolone.

\section{Acknowledgements}

This study was supported by grants from the Swedish Research Council, medicine proj. 4X11198, EU structural fund objective 1 program, Umeå University foundations, Västerbottens läns landsting, Umeå kommun. The study complies with Swedish law regarding ethical considerations in human experiments. 
Figures and Legends

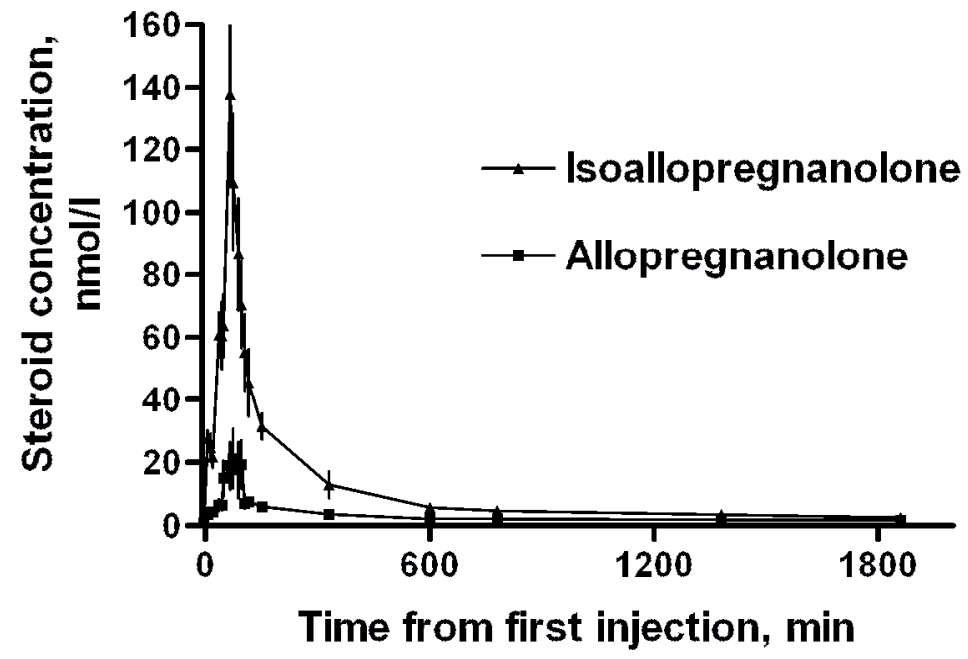

Figure 1

Figure 1. Mean serum concentrations of isoallopregnanolone (nmol/l) and allopregnanolone $(\mathrm{nmol} / \mathrm{l})$ measured at 19 time points. Concentrations are measured at baseline (-5 $\mathrm{min})$ before the first injection ( $0 \mathrm{~min})$ and until 1860 minutes after the first injection. Maximum concentration occurred at $67.7 \pm 4.1$ minutes for isoallopregnanolone and at $74.0 \pm 21.9$ minutes for allopregnanolone. 


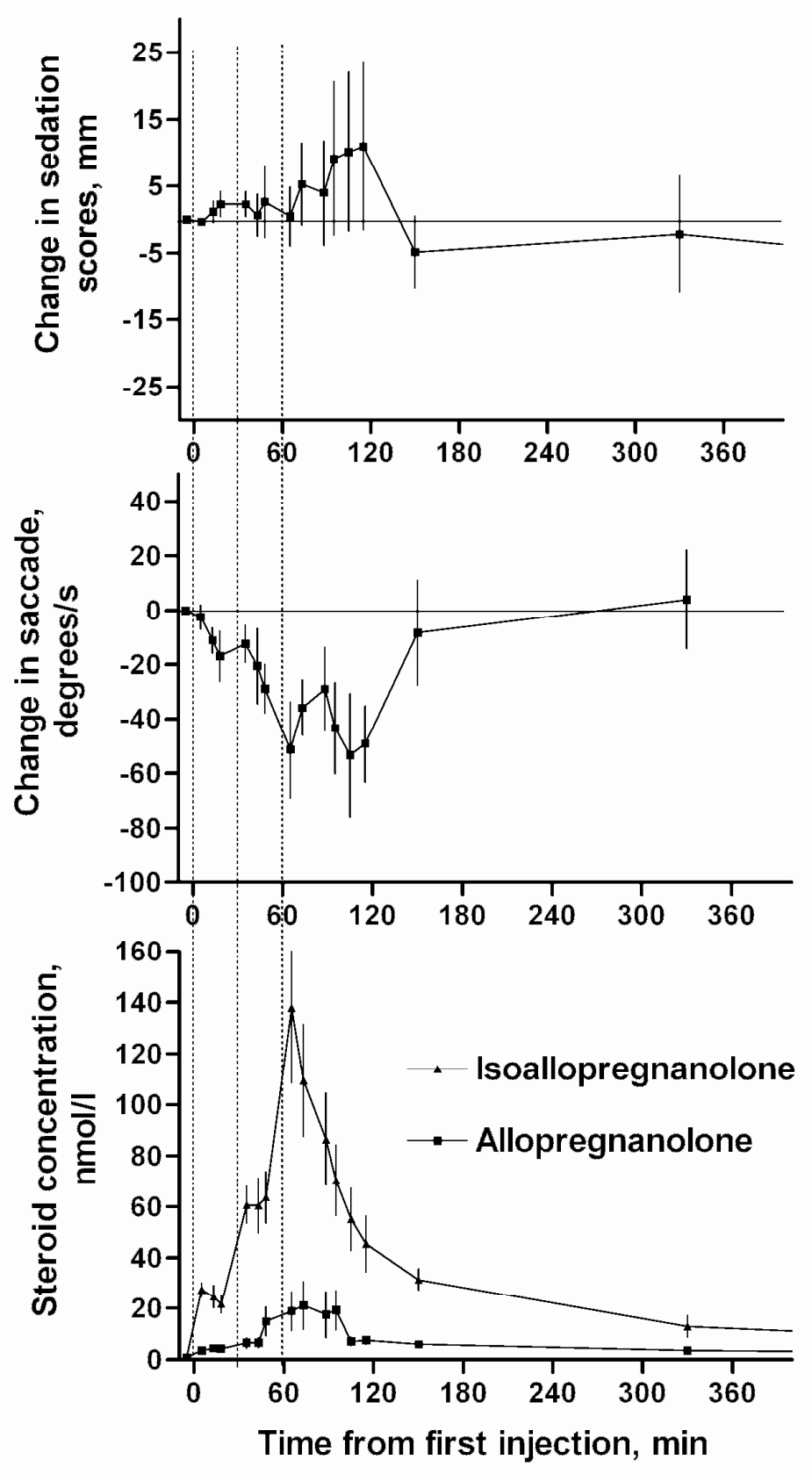

Figure 2

Figure 2. Mean (SEM) effects of isoallopregnanolone injections in women in the follicular phase on scored sedation (top panel), and saccadic eye velocity (SEV; middle panel) compared to the steroid concentrations (bottom panel). Dose $1(0.04 \mathrm{mg} / \mathrm{kg})$, dose $2(0.06$ $\mathrm{mg} / \mathrm{kg})$ and dose $3(0.10 \mathrm{mg} / \mathrm{kg})$ were given at 0,30 and 60 minutes and are indicated in the figure as dotted lines. No significant change in scored sedation was noted. There was an overall decrease in SEV from 5-115 minutes after the first injection $(F(14,70)=3.27 ; p<0.001)$. 

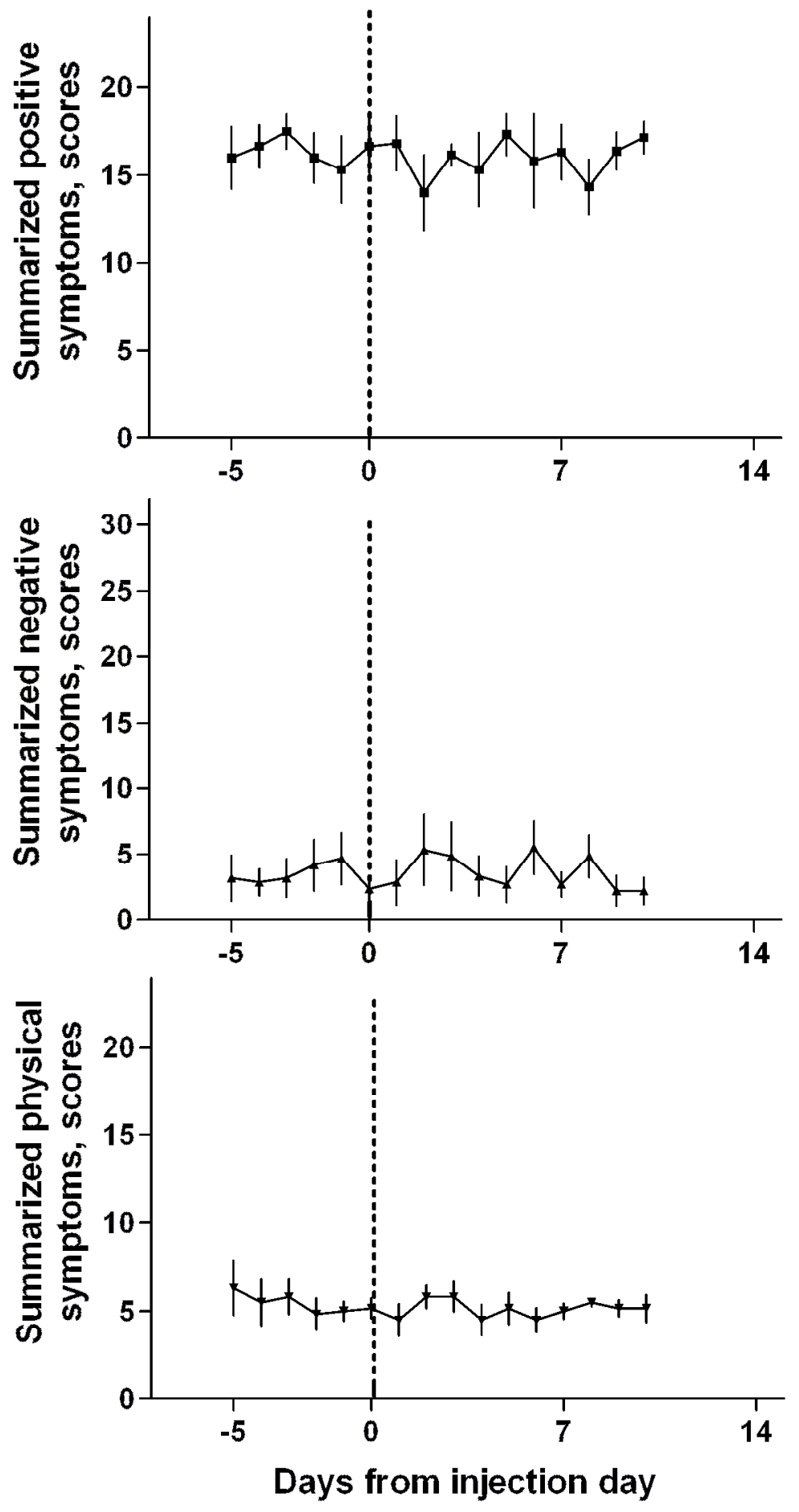

Figure 3

Figure 3. Mean (SEM) summarized positive, negative and physical symptoms from the daily ratings are plotted and centred round the test day in the follicular phase, five days prior to the test and 10 days after. There were no significant changes after the injections compared to the pre-test scores. Daily Ratings were made for menstrual bleeding and 15 other physical and 
mood changes during the whole menstrual cycle in which the experiment was performed.

Scores for cheerfulness, happiness, energy and interest in daily activities are summarized and plotted as positive symptoms (0-32). Scores for irritability, tension, fatigue and depressed mood are summarized and plotted as negative symptoms (0-32). Breast tenderness, change in appetite and swelling are summarized and plotted as physical symptoms (0-24). 
Table 1

Demographic data and physical characteristics of the study group ( $\mathrm{n}=6)$.

\begin{tabular}{|l|l|}
\hline Age, years, median (range) & 30.5 (23-39) \\
\hline Body mass index, $\mathrm{kg} / \mathrm{m}^{2}$, mean \pm SEM & $24.6 \pm 1,7$ \\
\hline Married (\%) & 50 \\
\hline Users of hormone contraceptives (\%) & 0 \\
\hline Tobacco users (\%) & 0 \\
\hline Number of children, n, mean \pm SEM & $0.83 \pm 0.4$ \\
\hline Reported menstrual cycle length, days, mean \pm SEM & $28.8 \pm 0.6$ \\
\hline Cycle length in test cycle, days, mean \pm SEM & $27.7 \pm 1.1$ \\
\hline Cycle day when the test was performed, median (range) & $9.5(6-13)$ \\
\hline
\end{tabular}


Table 2

Pharmacokinetic parameters of isoallopregnanolone and allopregnanolone in six subjects after three intravenous injections of isoallopregnanolone, representing a cumulative dose of 0.20 mg per kg body weight.

\begin{tabular}{llc}
\hline & $\begin{array}{l}\text { Isoallopregnanolone } \\
\text { Mean } \pm \mathrm{SD}\end{array}$ & $\begin{array}{c}\text { Allopregnanolone } \\
\text { Mean } \pm \mathrm{SD}\end{array}$ \\
\hline $\mathrm{C}_{0}\left(\mathrm{nmol} \cdot \mathrm{l}^{-1}\right)$ & $1.01 \pm 0.30$ & $0.80 \pm 0.13$ \\
$\mathrm{C}_{5}\left(\mathrm{nmol} \cdot \mathrm{l}^{-1}\right)$ & $27.5 \pm 6.7$ & $3.7 \pm 2.1$ \\
$\mathrm{C}_{35}\left(\mathrm{nmol} \cdot \mathrm{l}^{-1}\right)$ & $60.8 \pm 17.7$ & $6.6 \pm 4.7$ \\
$\mathrm{C}_{65}\left(\mathrm{nmol} \cdot \mathrm{l}^{-1}\right)$ & $138 \pm 71.7$ & $19.0 \pm 18.4$ \\
$\mathrm{C}_{\max }\left(\mathrm{nmol} \cdot \mathrm{l}^{-1}\right)$ & $143 \pm 73.0$ & $22.8 \pm 22.5$ \\
$\mathrm{t}_{\max }(\mathrm{min})$ & $67.7 \pm 4.1$ & $74.0 \pm 21.9$ \\
$\mathrm{t}_{1 / 2}(\mathrm{~min})$ & $847 \pm 599$ & $1079 \pm 527$ \\
$\mathrm{AUC}\left(\mathrm{nmol} \cdot 1^{-1} \cdot \min \right)$ & $21009 \pm 6031$ & $5853 \pm 4868$ \\
$\mathrm{CL}\left(\mathrm{ml} \cdot \mathrm{min}^{-1} \cdot \mathrm{kg}^{-1}\right)$ & $32.1 \pm 9.3$ & - \\
$\mathrm{V}_{\mathrm{d}}\left(1 \cdot \mathrm{kg}^{-1}\right)$ & $36.3 \pm 18.1$ & - \\
\hline
\end{tabular}

$\mathrm{C}_{0}=$ endogenous serum concentration; $\mathrm{C}_{5}, \mathrm{C}_{35}, \mathrm{C}_{65}=$ serum concentrations 5 minutes after each isoallopregnanolone injection; $\mathrm{C}_{\max }=$ maximum serum concentration; $\mathrm{t}_{\max }=$ time to achieve maximum serum concentrations; $\mathrm{t}_{1 / 2}=$ elimination half-life; $\mathrm{AUC}=$ area under the serum concentration/time curve from zero to infinity; $\mathrm{CL}=$ clearance; $\mathrm{V}_{\mathrm{d}}=$ volume of distribution. 
Table 3

Vital functions (mean \pm SEM) before and at several occasions after intravenous injections of isoallopregnanolone in six women during the follicular phase.

\begin{tabular}{|l|r|r|r|r|}
\hline Occasion & $\begin{array}{c}\text { Systolic blood } \\
\text { pressure, } \mathrm{mmHg}\end{array}$ & $\begin{array}{c}\text { Diastolic blood } \\
\text { pressure, } \mathrm{mmHg}\end{array}$ & $\begin{array}{c}\text { Heart rate } \\
\text { beats/min }\end{array}$ & $\begin{array}{c}\text { Respiration rate } \\
\text { number/min }\end{array}$ \\
\hline Baseline & $103 \pm 6.5$ & $73 \pm 3.5$ & $67 \pm 4.3 \S$ & $19 \pm 1.3$ \\
5 minutes & $107 \pm 5.1$ & $72 \pm 3.6$ & $65 \pm 3.7$ & $15 \pm 0.9$ \\
$\begin{array}{l}\text { After } 1^{\text {st }} \text { inj } \\
5 \text { minutes } \\
\text { After } 2^{\text {nd }} \text { inj }\end{array}$ & $103 \pm 3.5$ & $71 \pm 2.2$ & $61 \pm 4.0$ & $14 \pm 1.0$ \\
5 minutes \\
$\begin{array}{l}\text { After } 3^{\text {rd }} \text { inj } \\
35 \text { minutes } \\
\text { after } 3^{\text {rd }} \text { inj }\end{array}$ & $102 \pm 3.9$ & $71 \pm 3.0$ & $57 \pm 4.1$ & $17 \pm 1.9$ \\
& $102 . \pm 3.9$ & $70 \pm 3.0$ & $57 \pm 3.5$ & $16 \pm 1.0$ \\
$\begin{array}{l}9 \mathrm{~h} \text { after } 3^{\text {rd }} \\
\text { inj }\end{array}$ & $106 \pm 2.6$ & $69 \pm 4.1$ & $68 \pm 3.3$ & $13 \pm 1.5$ \\
\hline
\end{tabular}

$\S$ Statistically significant $(\mathrm{F}(5,25)=6.12 ; \mathrm{p}<0.001)$ change in heart rate during the course of the study day. 


\section{References}

Aluoja A, Shlik J, Vasar V, Kingisepp PH, Jagomagi K, Vasar E, Bradwejn J (1997) Emotional and cognitive factors connected with response to cholecystokinin tetrapeptide in healthy volunteers. Psychiatry Res 66:59-67.

American Psychiatric Association (1994) Diagnostic and Statistical Manual of Mental Disorders, 4th Edition. Washington, DC, pp 714-8.

Andreen L, Sundstrom-Poromaa I, Bixo M, Nyberg S, Backstrom T (2006) Allopregnanolone concentration and mood-a bimodal association in postmenopausal women treated with oral progesterone. Psychopharmacology (Berl).187:209-21.

Backstrom T (1976) Epileptic seizures in women related to plasma estrogen and progesterone during the menstrual cycle. Acta Neurol Scandinav 54:321-47.

Backstrom T, Andersson A, Andreen L, Birzniece V, Bixo M, Bjorn I, Haage D, Isaksson M, Johansson IM, Lindblad C, Lundgren P, Nyberg S, Odmark IS, Stromberg J, SundstromPoromaa I, Turkmen S, Wahlstrom G, Wang M, Wihlback AC, Zhu D, Zingmark E (2003a) Pathogenesis in menstrual cycle-linked CNS disorders. Ann N Y Acad Sci 1007:42-53.

Backstrom T, Andreen L, Birzniece V, Bjorn I, Johansson IM, Nordenstam-Haghjo M, Nyberg S, Sundstrom-Poromaa I, Wahlstrom G, Wang MD, Zhu D (2003b) The role of hormones and hormonal treatment in premenstrual syndrome. CNS Drugs. 17(5):325-42.

Backstrom T, Wahlstrom G, Wahlstrom K, Zhu D, Wang MD (2005) Isoallopregnanolone; an antagonist to anaesthetic effect of allopregnanolone in male rats. Eur J Pharmacol. 512:15-21.

Ball DM, Glue P, Wilson S, Nutt DJ (1991) Pharmacology of saccadic eye movement in man. 1. Effects of the benzodiazepine receptor ligands midazolam and flumazenil.

Psychopharmacology (Berl) 105:361-7.

Baloh RW, Sills AW, Kumley WE, Honrubia V (1975) Quantitative measurement of saccade amplitude, duration and velocity. Neurology 25:1065-70.

Baulieu EE, Robel P (1990) Neurosteroids: a new brain function? J Steriod Biochem Mol Biol 37:395-403.

Baulieu EE (1991) Neurosteroids: a new function in the brain. Biol Cell 71:3-10.

Beauchamp MH, Ormerod BK, Jhamndas K, Boegman RJ, Beninger RJ (2000) Neurosteroids and reward: allopregnanolone produces a conditioned place aversion in rats. Pharmacol Biochem Behav 67:29-35.

Belelli D, Lambert JJ (2005) Neurosteroids: endogenous regulators of the GABA(A) receptor. Nat Rev Neurosci 6(7):565-75.

Bicikova M, Dibbelt L, Hill M, Hampl R, Starka L (1998) Allopregnanolone in women with premenstrual syndrome. Horm metab Res. 30:227-30. 
Bitran D, Hilvers RJ, Kellogg CK (1991) Anxiolytic effects of 3 alpha-hydroxy-5 alpha[beta]pregnan-20-one: endogenous metabolites of progesteron thar are active at the $\mathrm{GABA}_{\mathrm{A}}$ receptor. Brain res 561:157-61.

Bradwejn J,Koszycki D, Shriqui C (1991) Enhanced sensitivity to cholecystokinintetrapeptide in panic disorder. Clinical and behavioral findings. Arch Gen Psychiatry 48:603-610.

Calogero AE, Palumbo MA, Bosboom AM, Burrello N, Ferrara E, Palumbo G, Petraglia F, D'Agata R (1998) The neuroactive steroid allopregnanolone supresses hypothalamic gonadotropin-releasing hormone releases through a mechanism mediated by the gammaaminobutyric acidA receptor. J Endocrinol 158:121-5.

Carboni E, Wieland S, Lan NC, Gee KW (1996) Anxiolytic properties of endogenously occurring pregnandiols in two rodent models of anxiety. Psychopharmacology (Berl) 126:173-8.

Carl P,Hogskilde S, Lang-Jensen T, Bach V, Jacobsen J, Sorensen MB, Gralls M, Widlund L (1994) Pharmacokinetics and pharmacodynamics of eltanolone (pregnanolone), a new steroid intravenous anaestetic, in humans. Acta Anaesthesiol Scand 38:734-41.

Chen SW, Rodriguez L, Davies MF, Loew GH (1996) The hyperphagic effect of 3 alphahydroxylated pregnane steroids in male rats. Pharmacol Biochem Behav 53:777-82.

Concas A, Pierobon P, Mostallino MC, Porcu P, Marino G, Minei R, Biggio G (1998) Modulation of gamma-aminobutyric acid (GABA) receptors and the feeding response by neurosteroids in Hydra vulgasris. Neuroscience 85:979-88.

Coperchot C, Young J, Calvel M, Wehrey C, Veltz JN, Touyer G, Mouren M, Prasad VV, Banner C, Sjovall J et al. (1993) Neurosteroids: 3 alpha-hydroxy-alpha-pregnan-20-one and its precursors in the brain, plasma, and steroidogenic glands of male and female rats. Endocrinology 133:1003-9.

Dayanithi G, Tapia-Arancibia L (1996) Rise in intracellular calcium via a nongenomic effect of allopregnanolone in fetal rat hypothalamic neurons. J Neurosci 16:130-6.

Droogleever Fortuyn HA, van Broekhoven F, Span PN, Backstrom T, Zitman FG, Verkes RJ (2004) Effects of PhD examination stress on allopregnanolone and cortisol plasma levels and peripheral benzodiazepine receptor density. Psychoneuroendocrinology 29(10):1341-4.

Epperson CN, Gueorguieva R, Czarkowski KA, Stiklus S, Sellers E, Krystal JH, Rothman DL, Mason GF (2006) Preliminary evidence of reduced occipital GABA concentrations in puerperal women: a 1H-MRS study. Psychopharmacology (Berl) 186:425-33.

Gee KW, Chang WC, Briton RE, McEwen BS (1987) GABA-dependent modulation of the Cl-ionophore by steroids in rat brain. Eur J Pharmacol 136:419-23.

Genazzani AD, Luisi M, Malavasi B, Strucchi C, Luisi S. Casarosa E, Bernardi F, Genazzani AR, Petraglia F (2002) Pulsatile secretory characteristics of allopregnanolone, a neuroactive steroid, during the menstrual cycle and in amenorrheic subjects. European Journal of Endocrinology 146:347-356. 
Gentles W, Thomas EL (1971) Commentary. Effect of benzodiazepines upon saccadic eye movements in man. Clin Pharmacol Ther 12:563-574.

Girdler SS, Straneva PA, Light KC, Pedersen CA, Morrow AL (2001) Allopregnanolone levels and reactivity to mental stress in premenstrual dysphoric disorders. Biol Psychiatry 49:788-97.

Glue P, White E, Wilson S, Ball DM, Nutt DJ (1991) Pharmacology of saccadic eye movements in man. 2. Effects of the alpha 2-adrenoceptor ligands idazoxan and clonidine. Psychopharmacology (Berl) 105:368-73.

Glue P, Bailey J, Wilson S, Hudson A, Nutt DJ (1992) Thyrotropin-releasing hormone selectively reverses lorazepam-induced sedation but not slowing of saccadic eye movements. Life Sci 50:25-30.

Grant DM, Beck JG, Davila J (2007) Does anxiety sensitivity predict symptoms of panic, depression, and social anxiety? Behav Res Ther 45(9):2247-55.

Gyermek L, Iriarte J, Crabbe P (1968) Structure - activity relationship of some steroidal hypnotic agents. J Med Chem 11:117-125.

Havlikova H, Hill M, Kancheva L, Vrbikova J, Pouzar V, Cerny I, Kancheva R, Starka L (2006) Serum profiles of free and conjugates neuroactive pregnanolone isomers in nonpregnant women of fertile age. J Clin Endocrinol Metab 91:3092-9.

Hellstadius AC (2000) Psykometrisk utprövning av Anxiety Sensitivity Index (Psychometric Evalution of Anxiety Sensitivity Index). Stockholm; Psykologiske Institutionen, Stockholms Universitet (Department of Psychology, University of Stockholm).

Hill M, Cibula D, Havlikova H, Kancheva L, Fait T, Kancheva R, Parizek A, Starka L (2007) Circulating levels of pregnanolone isomers during the third trimester of human pregnancy. Journal of steroid Biochemistry \& Molecular Biology 105:166-175.

Hommer DW, Matsuo V, Wolkowitz O, Chrousos G, Greenblatt DJ, Weingartner H, Paul SM (1986) Benzodiazepine sensitivity in normal human subjects. Arch Gen Psychiatry 43:542-51.

Jin CJ, Mackenzie PI, Miners JO (1997) The regio- and stereo-selectivity of C19 and C21 hydroxysteroid glucuronidation by UGT2B7 and UGT2B11. Arch Biochem Biophys 341(2):207-11).

Kokate TG, Svensson BE, Rogawski MA (1994) Anticonvulsant activity of neurosteroids: correlation with gamma-aminobutyric acid-evoked chloride current potention. J Pharmacol Exp Ther 270: 1223-9.

Lambert JJ, Belelli D, Hill-Venning C, Peters JA (1995) Neurosteroids and GABAA receptor funktion. Trends Pharmacol Sci 16:295-303. 
Lan NC, Gee KW, Bolger MB, Chen JS (1991) Differential responses of expressed recombinant human gamma-aminobutyric acidA receptors to neurosteroids. J Neurochem. 57:1818-21.

Lancel M, Faulhaber J, Schiffelholz T, Romeo E, Di Michele F, Holsboer F, Rupprecht R (1997) Allpregnanolone affects sleep in a benzodiazepine-like fashion. J Pharmacol Exp Ther. 282: 1213-18.

Landgren S, Wang MD, Backstom T, Johansson S (1998) Interaction between 3 alphahydroxy-5 alpha-pregnan-20-one and carbachol in the control of neuronal excitability in hippocampal slices of female rats in defines phases of the oestrus. Acta Physiol Scand. 162:77-88.

Le Foll F, Louiset E, Castel H, Vaudry H, Cazin L (1997) Electrophysiological effects of various neuroactive steroids on the GABA(A) receptor in pituitary melanotrope cells. Eur J Pharmacol 331:303-11.

Lundgren P, Stromberg J, Backstrom T, Wang MD (2003) Allopregnanolone-stimulated GABA-mediated chloride ion flux is inhibited by 3beta-hydroxy-5alpha-pregnan-20-one (isoallopregnanolone). Brain Res. 982:45-53.

Majewska MD, Harrison NL, Schwartz RD, Baker JL, Paul SM (1986) Steroid hormone metabolites are barbiturate-like modulators of the GABA receptor. Science. 232:1004-7.

Marshall RW, Griffiths AN, Richens A (1985) A microcomputer system to assess CNS dpression from analysis of the dynamics of saccadic eye movements. Br J Pharmacol. 20:304305.

Marshall RW, Richens A (1989) An IBM-based system for the generation, collection and analysis of saccadic and smooth pursuit eye movements. Br J Clin Pharmacol 20:304-305.

Masia SL, Perrine K, Westbrook L, Alper K, Devinsky O (2000) Emotional outbursts and pottraumatic stress disorders during intracarotid amobarbital procedure. Neurology 54:16913.

McCormack HM, Horne DJ, Sheather S (1988) Clinical applications of visual analogue scales: a critical review. Psychol Med 18:1007-19.

di Michele F, Verdecchia M, Dorofeeva M, Costamagna L, Bernardi G, Curatolo P et al (2003) GABA(A) receptor active steroids are altered in epilepsy patients with tuberous sclerosis. J Neurol Neurosurg Psychiatry 74:667-70.

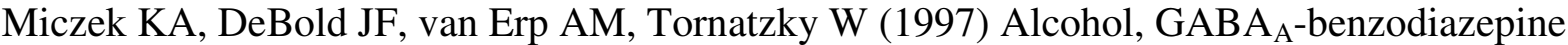
receptor complex, and aggression. Recent Dev Alcohol 13:139-71.

Miczek KA, Fish EW, DeBold JF (2003) Neurosteroids, GABA A $_{\text {receptors and escalated }}$ aggressive behavior. Horm Behav 44: 242-57. 
Monteleone P, Luisi S, Tonetti A, Bernardi F, Genazzani AD, Luisi M, Petraglia F, Genazzani AR (2000) Allopregnanolone concentrations and premenstrual syndrome. Eur J Endocrinol. 142:269-73.

Murphy BE, Abbott FV, Allison CM, Watts C, Ghadirian AM (2004) Elevated levels of some neuroactive progesterone metabolites, particularly isopregnanolone, in women with chronic fatigue syndrome. Psychoneuroendocrinology 29(2):245-68.

Nappi RE, Petraglia F, Luisi S, Polatti F, Farina C, Genazzani AR (2001) Serum allopregnanolone in women with postpartum "blues". Obstet Gynecol 97:77-80.

Niwa T, Yabusaki Y, Honma K, Matsuo N, Tatsuta K, Ishibashi F, Katagiri M (1998) Contribution of human hepatic cytochrome $\mathrm{P} 450$ isoforms to regioselective hydroxylation of steroid hormones. Xenobiotica 28:539-47.

Nyberg S, Wahlstrom G, Backstrom T, Sundstrom Poromaa I (2004) Altered sensitivity to alcohol in the luteal phase among patients with premenstrual dysphoric disorder.

Psychoneuroendocrinology 29:767-77.

Nyberg S, Backstrom T, Zingmark E, Purdy RH, Sundstrom Poromaa I (2007)

Allopregnanolone decrease with symptom improvement during placebo and gonadotropinreleasing hormone against treatment in women with severe prementrual syndrome. Gynecol Endocrinol. 23:257-66.

Ottander U, Poroma IS, Bjurulf E, Skytt A, Backstrom T, Olofsson JI (2005)

Allopregnanolone and pregnanolone are produced by the human corpus luteum. Mol Cell Endocrinol 239:37-44.

Parizek A, Hill M, Kancheva R, Havlikova H, Kancheva L, Cindr J, Paskova A, Pouzar V, Cerny I, Drbohlav P, Hajek Z, Starka L (2005) Neuroactive pregnanolone isomers during pregnancy. J Clin Endocrinol Metab. 90:395-403.

Peters JA, Kirkness EF, Callachan H, Lambert JJ, Turner AJ (1988) Modulation of the GABAA receptor by barbiturates and pregnane steroids. Br J Pharmacol 94:1257-69.

Peterson RA, Reiss S (1992) Anxiety Sensitivity Index Manual (2nd ed.) Worthington, OH: International Diagnostic Systems.

Purdy RH, Moore PH Jr, Rao PN, Hagino N, Yamaguchi T, Schmidt P, Rubinow DR, Morrow AL, Paul SM (1990) Radioimmunoassay of 3alpha-hydroxy-5alpha-pregnan-20-one in rat and human plasma. Steroids 55:290-296

Purdy RH, Morrow L, Moore PH, Paul SM (1991). Stress-induced elevation of aminobutyric acid type A receptoractive steroids in the brain. Proc. Natl. Acad. Sci. USA. 88:4553-4557.

Radu D, Ahlin A, Svanborg P, Lindefors N (2002) Anxiogenic effects of the CCK(B) agonist pentagastrin in humans and dose-dependent increase in plasma C-peptide levels.

Psychopharmacology (Berl) 161:396-403. 
Rapkin AJ, Morgan M, Goldman L, Brann DW, Simone D, Mahesh VB (1997) Progesterone metabolite allopregnanolone in women with premenstrual syndrome. Obstet Gynecol. 90:70914.

Reiss S, Peterson RA, Gursky DM, McNally (1986) Anxiety sensitivity, anxiety frequency and the prediction of fearfullness. Behaviour Research and Therapy 24:1-8.

Richens A, Mercer AJ, Jones DM, Griffiths A, Marshall RW (1993) Effects of zolpidem on saccadic eye movement and psychomotor performance: a double-blind, placebo controlled study in healthy volunteers. Br K Pharmacol 36:61-5.

Rodgers RJ, Johnson NJ (1998) Behaviorally selective effects of neuroactive steroids on plusmaze anxiety in mice. Pharmacol Biochem Behav 59:221-32.

Romeo E, Strohle A, Spalletta G, di Michele F, Hermann B, Holsboer F, Pasini A, Rupprecht $\mathrm{R}$ (1998) Effects of antidepressant treatment on neuroactive steroids in major depression. Am J Psychiatry 155:910-3.

Roy-Byrne PP, Cowley DS, Greenblatt DJ, Shader RI, Hommer D (1990) Reduced benzodiazepine sensitivity in panic disorder. Arch Gen Psychiatry 47:534-8.

Schule C, di Michele F, Baghai T, Romeo E, Bernardi G, Zwanzger P, Padberg F, Pasini A and Rupprecht $R$ (2003) Influence of sleep deprivation on neuroactive steroids in major depression. Neuropsychopharmacology 28: 577-281.

Spielberger C (1983) State-Trait Anxiety Inventory (Form Y), Mind Garden, Palo Alto, CA.

Spitzer RL, Williams JB, Kroenke K, Linzer M, deGruy FV III, Hahn SR, Brody D, Johnson JG (1994) Utility of a new procedure for diagnosing mental disorders i primary care. The PRIME-MD 1000 study. JAMA 272:1749-1756.

Strohle A, Romeo E, di Michele F, Pasini A, Yassouridis A, Holsboer F, Rupprecht R (2002) GABA(A) receptor-modulating neuroactive steroid composition in patients with panic disorder before and during paroxetine treatment. Am J Psychiatry 159:145-7.

Stromberg J, Haage D, Taube M, Backstrom T, Lundgren P (2006) Neurosteroid modulation of allopregnanolone and GABA effects on the GABA-A receptor. Neuroscience 142:73-81.

Sundstrom I, Nyberg S, Backstrom T (1997) Patients with premenstrual syndrome have reduced sensitivity to midazolam compared to control subjects. Neuropsychopharmacology $17: 370-81$.

Sundstrom I, Andersson A, Nyberg S, Ashbrook D, Purdy RH, Backstom T (1998) Patients with premenstrual syndrome have a different sensitivity to a neuroactive steroid during the menstrual cycle compared to control subjects. Neuroendocrinology 67:126-38.

Sundstrom I, Backstrom T (1998) Patients with premenstrual syndrome have decreased saccadic eye velocity compares to control subjects. Biol Psychiatry 44:755-764. 
Sundstrom I, Nyberg S, Bixo M, Hammarback S, Backstrom T (1999a) Treatment of premenstrual syndrome with gonadotropinreleasing hormone agonist in a low dose regimen. Acta obstet Gynecol Scand. 78:891-9.

Sundstrom I, Spigset O, Andersson A, Appelblad P, Backstrom T (1999b) Lack of influence of menstrual cycle and premenstrual syndrome diagnosis on pregnanolone pharmacokinetics. Eur J Clin Pharmacol 55:125-30.

Taylor S, Koch WL, McNally RJ (1992) How does anxiety sensitivity vary across the anxiety disorders? Journal of Anxiety disorders 6:249-59.

Timby E, Balgard M, Nyberg S, Spigset O, Andersson A, Porankiewicz-Asplund J, Purdy RH, Zhu D, Backstrom T, Sundstrom-Poromaa I (2006) Pharmacokinetic and behavioral effects of allopregnanolone in healthy women. Psycopharmacology (Berl) 186:414-24.

Torres JM, Ruiz E, Ortega E (2001) Effects of CRH and ACTH administration on plasma and brain neurosteroid levels. Neurochem Res 26(5):555-8.

Tsuchiya Y, Nakajima M, Yokoi T (2005) Cytochrome P450-mediated metabolism of estrogens and its regulation in human. Cancer Lett. 227:115-24.

Turkmen S, Lundgren P, Birzniece V, Zingmark E, Backstrom T, Johansson IM (2004) 3beta20beta-dihydroxy-5alpha-pregnane (UC1011) antagonism of the GABA potentiation and the learning impairment induced in rats by allopregnanolone. European $\mathrm{J}$ of Neuroscience 20:1604-1612.

Vallee M, Rivera JD, Koob GF, Purdy RH, Fitzgerald RL (2000) Quantification of neurosteroids in rat plasma and brain following swim stress and allopregnanolone administration using negative chemical ionization gas chromatography/mass spectrometry. Analytical Biochemistry 287:153-166.

Wang MD, Backstrom T, Landgren S (2000) The inhibitory effects of allopregnanolone and pregnanolone on the population spike, evoked in the rat hippocampal CA1 stratum pyramidale in vitro, can be blocked selectively by epiallopregnanolone. Acta Physiol Scand 169(4):33341.

Wang MD, He YJ, Eisenman LN, Fields C, Zeng CM, Mathews J, Benz A, Fu T, Zorumski E, Steinbach JH, Covey DF, Zorumski CF, Mennerick S (2002) 3 beta-hydroxypregnan steroids are pregnenolone sulfate-like GABAA receptor antagonists. Journal of Neurosciense 22(9):3366-3375.

Watanabe K, Nagakura Y, Hiura N, Tsuchiya S, Horie S (2000) Stimulation of gastric acid secretion by progesterone metabolites as neuroactive steroids in anesthetized rats. J Physiol Paris 94:111-6.

Wenzel RR, Bartel T, Eggebrecht H, Philipp T, Erbel R (2002) Cental nervous side effects of midazolam during transesophageal echocardiography. J Am Soc Echocardiogr 15(10 Pt 2):1297-300. 
Wieland S, Lan NC, Mirasedeghi S, Gee KW (1991) Anxiolytic activity of the progesteron metabolite 5 alpha-pregnan-3 alpha-o1-20-one. Brain Res 565:263-8.

Wihlback AC, Sundstrom-Poromaa I, Nyberg S, Backstrom T (2001) Sensitivity to a neurosteroid is increased during addition of progesterone to postmenopausal hormone replacement therapy. Neuroendocrinology 73:397-407.

Yamazaki H, Shimada T (1997) Progesterone and testosterone hydroxylation by cytochromes P450 2C19, 2C9, and 3A4 in human liver microsomes. Arch Biochem Biophys 346:161-9 